\title{
Correction to: Cues to individual identity in songs of songbirds: testing general song characteristics in Chiffchaffs Phylloscopus collybita
}

\author{
Alexandra Průchová ${ }^{1} \cdot$ Pavel Jaška ${ }^{1,2} \cdot$ Pavel Linhart ${ }^{3,4}$ (D) \\ Published online: 11 September 2018 \\ (c) Dt. Ornithologen-Gesellschaft e.V. 2018

\section{Correction to: J Ornithol (2017) 158:911-924 https://doi.org/10.1007/s10336-017-1455-6}

In the original publication of this article, the Acknowledgements section is mentioned as

"P. L. was funded by the Czech Science Foundation (GA14-27925S), the Ministry of Agriculture of the Czech Republic (MZERO0716), and the National Science Centre, Poland (2015/19/P/NZ8/02507). A. P. was supported by the Grant Agency of the University of South Bohemia (GAJU 151/2016/P). The experiments comply with the current laws of the Czech Republic and the European Union regarding research on animals. We would like to thank Pawel Szymański for classification of the song syllables used for the inter-observer reliability analysis. We also greatly appreciate the English editing and comments of Robert G. West."

But the correct Acknowledgements should be "P. L. was funded by the Czech Science Foundation (GA1427925S), the Ministry of Agriculture of the Czech Republic (MZERO0716), and by the National Science Centre, Poland (under Polonez fellowship reg. no UMO-2015/19/P/ NZ8/02507 funded by the European Union's Horizon

The original article can be found online at https://doi.org/10.1007/ s10336-017-1455-6.

Pavel Linhart

pavel.linhart83@gmail.com

1 Department of Zoology, Faculty of Science, University of South Bohemia, Branišovská 1760 , 37005 České Budějovice, Czech Republic

2 Nature Conservation Agency of the Czech Republic, PLA Administration Slavkovský les, Hlavní 504, 35301 Mariánské Lázně, Czech Republic

3 Faculty of Biology, Department of Behavioural Ecology, Adam Mickiewicz University, Umultowska 89, 61-614 Poznan, Poland

4 Department of Ethology, Institute of Animal Science, Přátelství 815, 10400 Praha Uhříněves, Czech Republic
2020 research and innovation programme under the Marie Skłodowska-Curie grant agreement No 665778). A. P. was supported by the Grant Agency of the University of South Bohemia (GAJU 151/2016/P). The experiments comply with the current laws of the Czech Republic and the European Union regarding research on animals. We would like to thank Paweł Szymański for classification of the song syllables used for the inter-observer reliability analysis. We also greatly appreciate the English editing and comments of Robert G. West." 